\title{
Paradise Lost
}

By C.A.O. van Nieuwenhuijze, Leiden: Brill, 1997, 421 pp.

In Paradise Lost, a collection of rewritten and updated articles spanning a period of twenty-five years, C.A.O. van Nieuwenhuijze attempts to tackle issues of identity and interaction in the Arab-Islamic world. Together they constitute phenomena of virtual reality, reifying concepts as instruments of intelligibility, being at once the product and frame of human intellect and action (p. 
3). Both components, as the common thread which ties and pervades his work, comprise the conceptual framework within which the "forever problematic" relationship between the Middle East and a revitalizing Islam on the one hand, and a Western Europe undergoing a post-Christian, postmodern phase, on the other, is probed.

This nexus of collective identity and interaction manifests a "logical complementarity" inasfar as both presuppose and negate each other (p. 1). Identity evokes an all encompassing eclectic representation of an individual's or collectivity's cosmos, be it in the form of some pars pro toto (nation, polity, economy, or culture; umma or din) or an intentional comprehensive indication (lifestyle; patrimoine; turath). In recognizing no other beyond its cosmic domain, identity connotes a seemingly timeless and placeless unicity which frequently bestows upon it an impressive though mistaken aura of static permanence and absoluteness (p. 2). Interaction conversely represents the "practice of identity as a plural phenomenon" (p. 405) and thus incorporates all the complexities which emanate from the dynamics of a highly variable reality. The formulae it gives rise to pars pro toto are correspondingly much more fluid (communication, harmony, strife, domination) or reflective of inherent, largely imbalanced ambiguities (mission civilisatrice; development aid or, euphemistically, cooperation; $\left.d a^{*} w a h\right)$. In contradistinction to identity significations asserting the positive aspects of constituency (i.e., what one is), these interactional code words are summary evocations arrived at by the intervening perception of a counteridentity of the "other" (i.e., what one is not). Hence, it gives rise to polar images of binary opposites of such orders as Greek vs. barbarian; Islam vs. jahiliyah; or dar al-Islam vs. dar al-harb. In and of themselves, interactional identifications bear limited significations to those concerned except in tacit conjunction with each term's opposition (p. 2). In other words, self-identification is arrived at by detour. Consequently, interaction is relegated to an instrumental role on behalf of a pre-established and, in most cases as Arab/Islamic-European historical experience has shown, dominating self-centered structure. As a result, "the fundamental complementarity between identity and interaction is neglected, and with it the contingency inherent in identity" (pp. 2-3). Entrenchment in the face of an aggressive ethnocentrism, henceforth, becomes the order of the day.

Intellectual exploits of Western Enlightenment elevated objectification to the highly esteemed means toward ethnocentrically motivated mastery over "reality." Its basic mode of analysis combined empirical observation with critical rigor and methodological empathy and an overwhelming penchant to universalize conclusions-method being confused for truth. In the process, social sciences and Oriental studies came to reflect national categories contrived by an 
assertive modem West in a self-perpetuating subject-object relationship. Global changes associated with the world wars, decolonization, and skepticism about the relevance of alien methodologies to the Arab/Islamic context, in addition to the failure of presumptions underlying objectification to be adequately validated, threw the whole field into disarray, subjecting concomitant identifiers to the forces of wear and tear. This process did not leave either side unscathed, engulfing both in an identity crisis. To a European civilization committed to a modern nonfoundational secular world, beyond a limit currently being experienced in random yet disturbing symptoms, modernity has increasingly proven less valid and may actually be on its way out (pp. 7-8). This crisis is experienced in the form of a "half-way house" postmodern condition of "indefinite duration," reflecting the unsustainability of one paradigm, Western modernity, coupled to the unforseeability of its successor (pp. 389, 392), i.e., no alternative as of yet seems to be on the horizon. On the Arab side, Islam is currently proving the only viable frame of reference, especially in light of the failure of imported alternatives. The challenge, however, is to re-effectuate the timeless and ubiquitous truth of Islam while accounting for historical and current Western impact. At heart is the identification of a point of departure representing absolute truth, toward rethinking the lifestyle and making a fresh start. Yet in such a search for "sustainable authenticity," Western "imponderables" as have gained global sway stand to be accommodated even as they represent irrelevant premises (pp. 9-10).

A stable identity structure remains a necessary condition and a prerequisite to a viable dialogue between any two civilizations. Dialogue as a voluntary conciliatory input into an interactive process presupposes the actual or virtual existence of nonconflictual common grounds This implies that controversial basics will have to be eschewed if such interaction is to occur in the first place. In essence, this means that dialogue is "noncommittal." Its benefit, however, lies in the hope that through enhancing reciprocal empathy, overriding gains may accrue from conflict avoidance (p. 10). In ignoring basics, however, one is left to wonder as to whether much could be commonly built upon beyond nonconflictive co-existence; especially so, should a moment of truth strike at heart. One such instance, discussed rather extensively by van Nieuwenhuijze, is the "development" policies adopted by many Arab/Muslim countries, which in their subsequently exposed irrelevance turned out to reflect nothing more than a Westem worldview of economism, a view which ignores the "noneconomic" realities of the recipient societies (p. 11). Under such conditions, where one side - in this case, the Arabs - is admittedly incapable of producing knowledge whether through a traditional system of education or a modern one, dialogue can only collapse into a monologue. This compromises the identity 
structure of one party to the dialogue, especially when there is no reward for sticking one's neck out by raising the deeper questions to which there are no ready or available answers. Fundamentalists, according to van Nieuwenhuijze, are no solution to this problem.

Essentially, the above is how van Nieuwenhuijze articulates the dilemmas facing a civilizational dialogue and constructs his conceptual framework (ch. 1). The rest of the book, henceforth, builds on this theme. However, the fact that the subsequent chapters constitute a collection of articles rather than a sequential order of breakdowns leads frequently to some repetitiveness and redundancies which unnecessarily extend the length of the book. The compilation is divided into three parts. Part 1 (chs. 2-9) probes the dynamics of the Arab/lslamic civilization and the alternate perceptions of development and change. This includes the implications of modern science in a non-Western context and the ambiguities which arise in crisis form due to external Western impingements. Islamic revitalization is also examined in this part, as a means of repelling alien forces while reasserting and safeguarding a collective identity facing the threat of absorption into that of an aggressive "other." Chapter 2 introduces the cosmic distinctions between the "self-directedness" of Western man steeped in hubris and the "other-directedness" of the Muslim, embedded in a universe of creation, revelation, and ultimate judgment (pp. 34; 19-21). Change, in the framework of these alternative weltanschuungs, reflects different understandings, which not infrequently lead many to project a static representation of the Middle East (the suitability of this term as applied to the Arab/Islamic world is subject to ethnocentric controversy; van Nieuwenhuijze, while using the term is aware of its ethnocentric implications, p. 51) as a place where progressive change does not occur. Thus, van Nieuwenhuijze makes a corrective distinction between the Western conception of change as a unidirectional and irreversible process, instrumentalized by man to shape the world to his own projected image, and that of Muslims as an occasionalistic "act" of restoration. Routinization is perceived as having a deviant effect on Islam, which calls for a mujaddid, a renewer, to arise, act, and redress. Thus, while Western man, with time as his alleged instrument, is an innovator and planner, the Muslim is a restorer. Under the apparent stability of Islam, a hidden dynamic of change as act, not process, is underscored. Consequently, the crucial question is whether there can be any common ground between the two (pp. 24, 34).

Chapters 3 and 4 proceed to highlight the contemporary historical specificities of the Middle East region compared to the rest of the Third World (a term falling out of current use) (ch. 3), and where Islam is a particular determinant of culture and civilization (ch. 4). Unlike other colonized societies and an important factor in the nature of the Arab/Islamic-Western colonial experience 
is that the imbalanced interaction had occurred between two competing yet kindred civilizations. Hence, the superimposition of Western historical experiences and structures, such as "development" and "states," on a unique and distinct civilizational identity can produce only disappointing outcomes. The Westem development paradigm remains worlds apart from Arab-Muslim experiences and understandings. To the extent that it is essentially economistic and ignores its own relative and particularistic idiosyncrasies, it has been doomed to failure. As van Nieuwenhuijze puts it, "ethnocentrism on either side informs a permanently competitive match" (p. 35).

This calls for an "exercise in clarification" in order to render information pertaining to one setting intelligible and manageable to those belonging to another. Thus, chapter 5 attempts to provide an understanding for terms like secularization and secularism in their proper Westem context, and from thereon to mark the difference between Christian or post-Christian civilization and the Islamic civilization. After reviewing some of the major current trends in Islam, van Nieuwenhuijze hypothesizes that the real conflict in contemporary Middle Eastern civilization is not between "reactionary" fundamentalists and "progressive" Westernizers, but rather an identity conflict comprising essentialism versus secularization, the latter pair constituting the ambiguity that marks a potentially fertile third position squeezed between the former two (pp. 81-82).

A convergence approach suggested by van Nieuwenhuijze (ch. 6) envisages the combined images of self and other on either side as the instruments for both interaction proper and its scholarly description and analysis. This is meant to avoid distortions frequently besetting description and thwarting dialogue (pp. 124-25). According to him, notions of "Islam" and "West" raise more problems than they solve. Self-reinforcing perceptions, simplifications, and stereotyping in addition to media influences have rendered encounter situations between the two civilizations problematic. At the heart of the confusion is "conceptual access" as a necessary condition for mutual understanding (p. 96). Common rationality thus is necessary in order to guard against hostile opposing representations (p. 124).

Rationality inevitably brings up the issue of science (ch. 7). Van Nieuwenhuijze makes the important point that it was not science per se which led to secularism and secularization. Rather, the main culprit was the presupposing view of man as a demiurge which, owing its roots to the Christian notion of "creature," gained in significance during the Renaissance and eventually culminated in modernity (i.e., humanism). Thus, while in the Western historical perception science owed its flowering to the liberation from the shackles of religion and dogma, one must be more circumspect when raising the issue of Islam and science. Though in some respects problematic, the rela- 
tionship between the two is not what it has been in the Occident. In the Islamic historical experience science may have been neglected, but it was not opposed. Inasfar as there has been a "tectonic fault" in the Islamic civilization, it was largely between Orthodoxy and mysticism rather than science. The problematic question remains, however, as to whether Islam can grapple with modern science-if not in its outlook then at least in its secular inspiration (pp. 127-35).

The final chapter in part 1 (ch. 9) is a follow-up on chapter 8, where van Nieuwenhuijze discusses in some length the distinctions between "Islamism" and mainstream Islam. Chapter 9 is basically a review of the extensive multivolumed study of fundamentalism, sponsored by the American Academy of Arts and Science and edited by Martin Marty and R. Scott Appleby. He undergoes the exercise within a postmodern framework and argues that as a broad phenomenon witnessed among members of different faiths, "fundamentalism" as a term is simply a "totalizing figment by means of which Westerners try to come to terms ... ethnocentrically, with what is seen as a range of specific instances of non-Westerners' response to the Western impact" (p. 186).

Part 2 of the book (chs. 10-15) concentrates on the intercultural relations between the Middle East and Europe. Chapter 10 offers a presentation of what is meant by "sociocultural identity" or authenticity and its role in intercultural processes, particularly during the Western colonial period, together with a summary presentation of the Arab case in an attempt to assess interactive potential. According to van Nieuwenhuijze, the nature of the relationship between the Arab and European sociocultural identities is characterized by a basic affinity appearing as an ambiguity of convergence and divergence-a sort of love-hate relationship (p. 196). Chapter 11 looks at the Euro-Arab Symposium which had been held in Hamburg in April 1983, within the perspective of the long-standing relationship between Europeans and Arabs as a case of enduring cultural interaction. His purpose, as he identifies it, is to foster understanding of the constraints and prospects of cultural encounters as a main feature of global interdependence. Chapters 12 and 13 present the phenomenon of interculturality as an experience which challenges the premise that one's own culture is unique and looks at long-standing cross-Mediterranean transaction as a case in point (ch. 12). This is followed by a discussion of the factors obstructing or facilitating sociocultural intercourse (ch. 13). In the same vein, chapter 14 follows up on the issue but more so from a religious Muslim-Christian historical encounter perspective. Finally, chapter 15 delves into the prospects for a Euro-Arab dialogue. The author concludes that much remains to be done in this regards, especially when clear goal-setting (complicated by both sides trying to avoid or impose certain issues, e.g., the 
Arab-Israeli conflict, or not being able to identify what is hoped to be achieved) remains illusive.

Part 3 of the book (chs. 16-21) attempts to consider the implications for Oriental and development studies and the new demands arising from the perceptual and methodological retooling needed to meet them. In chapter 16, the author observes that there is a good measure of reciprocity in the processing of information and in the ensuing image-making of the other on both sides. However, they do not constitute symmetrical formations. Vital interests are more at play in the Arab world in their contestation of the image of the West than vice versa; no doubt this is due to the power asymmetry. Symmetry as a point of departure for a dialogue reflects, therefore, a simplistic representation of the matter (p. 138). Chapter 17 assesses the significance of the "irreversible" trend toward One World interaction and interdependence on one hand and the natural and ineradicable ethnocentrism informing any group or collectivity on the other, for work being and to be done in humanities and social sciences. Education and curricular adjustments are to play an important role in allowing scholarship to become more effectively interactive.

Finally, chapters 18 through 20 bring up the controversial issue of Oriental studies. The main difficulty facing Oriental studies is not merely that it represents a purposeful and systematic attempt at deceit and falsification, as Edward Said has charged, but more so that it incorporates the problem of double frame of reference (p. 348). While there may have been sincere attempts at understanding and representing the "other," the fact that such knowledge had to be translated into and for a different context with its own frame of reference has contributed more rather than less to misunderstandings. Overcoming these pitfalls calls for a move toward intersubjectivity where Arabs are not simply objects of study but actual participants in the effort at understanding. Furthermore, the author stresses the importance of developing a field of Occidental studies to match that of the Oriental counterpart. In an interactive One World system, it is well nigh for non-Westerners to develop the vital interest in knowing "the other"- the West (p. 354). In this effort, Western claims to a universality of understanding are to give grounds to intercultural communication and regional studies (not in the military-strategic sense adopted by American academic institutions) which account for the persistence among mankind of multiple and various ways of gaining and expressing understanding (ch. 19; p. 362). In this respect, the inherent ethnocentrism of cross-cultural studies must be overshadowed by a "forward looking" agenda arising from the concern that in a global village, intercultural transactions and their instrument, cultural studies, are bound to acquire increasingly vital significance for the survival of mankind (ch. 20; p. 365). In the rest of the chapter, the author 
proceeds to suggest methods by which this may be achieved. Finally, chapter 21 re-examines the concept of development while stressing the significance of culture to the understanding and practice of development. Van Nieuwenhuijze also looks at why previous developmental projects had failed in light of their reductive and economistic impulses and concludes by listing a group of entries (in an annex) to be studied by interdisciplinary teams of researchers and policy-makers.

Van Nieuwenhuijze's work raises important and interesting issues, particularly as pertaining to intercivilizational relations, and is quite realistic in pointing out problems facing a fruitful dialogue between Arabs/Muslims and Europe. However, for all the apparent and (one may add) sincere endeavor exhibited by the author at tackling sensitive and controversial issues in as neutral a fashion as possible, it remains clear that he cannot maintain a mental distance between his knowledge structure or system of intelligence and the issues he raises or approaches. This is not meant to criticize but to highlight the natural limitations caused by the problem that van Nieuwenhuijze actually recognizes but cannot avoid-the double frame of reference. Conceptual, definitional, procedural, and substantive difficulties arise as a consequence, which serve in many cases to undermine serious efforts and waste significant energies. Frustration builds up when this culminates in a vicious circle of mutual recriminations as both sides end up where they had started from.

Van Nieuwenhuijze's approach suffers several limitations, the most serious of which is reductionism. From such a methodological base follow the rest of the faults. For instance, universality in Islamic terms connotes revelation (i.e., from outside of history and sociocultural formations); supreme and unadulterated Truth (i.e., no tampering with it has taken place over time and space); and finality (last revelation, seal of Prophets doctrine, and perfection). From this follows Islam's claim to absolute truth. In this sense, universality is a closed, not an open, system. Van Nieuwenhuijze's definition of universalism as a "wishful claim to uniqueness," in grudging accommodation with manifest plurality of entities (p. 99), and as such constitutes an open sociocultural system, may perhaps be only partially, though reductively, true as far as the umma as a cognitive sociocultural body is concerned. However, a holistic view of Islam must always consider its universality (normative closure) and derived universalism (cognitive openness) as two components of a unity. Otherwise, simply considering the latter on its own would very well lead to reductive fallacies. The cultural approach which van Nieuwenhuijze adopts and applies to Islam and Muslims' conception of themselves inevitably superimposes social theory as the frame of reference. Consequently, Arabs and Muslims end up being rep- 
resented rather than representing themselves. Could this be more of the same Orientalism?

In different ways, more could be said about other controversial concepts such as secularism and secularization. As van Nieuwenhuijze observes, these concepts find their roots not only in the pagan history of Europe, but also in the ambiguous Christian view of man as God-oriented and, through the doctrine of original sin, as turning away from God. In these terms, they are completely alien to Islam. Yet many tend to associate worldly concerns of Muslims with manifestations of those concepts rather than with the innate worldly aspects of the faith. After all, in addition to being otherworldly, Islam takes pride in being a worldly religion as well (din wa dunya). Perhaps a more suitable conceptual usage in dealing with Muslims' sociocultural concerns would be "worldliness" (dunya; as an otherworldly derivative manifest and embodied in the Ummah) as opposed to secularism and its materialistic derivatives.

Van Nieuwenhuijze's reductionism further leads him to fall into procedural and substantive pitfalls. In arguing for a "workable" truth as a necessary requisite for interaction, he seems to be calling for good old-fashioned pragmatism. Religious Truth, in this case, is subordinated to practical requirements with (mis)interpretations serving as religious sanctioning for a cognitive-normative hierarchy, i.e., rationality. Moreover, he suggests, as a means of civilizational convergence, that claims against the existence of any truth on the one hand, and claims to truth on the other, be dropped, both being a posture of hubris (p. 124). But dropping the former claims would beg the question: Where then lies the truth? Dropping the latter claims would beg the opposite question: What then does revelation constitute? While it may be true that to make a claim to truth as interpretation is one thing, and to make a claim to Truth as revelation is another, both, however, are symbiotically linked and can only be defined in respect to each other. Thus, if the answer to the first question is that "truth" is out there but that no one has access to it, then this is tantamount to saying there is no truth, opinion consequently and inevitably being held in secular supremacy. By detour, we are back to a situation in which claims to the absence of truth are asserted though deceptively so, while claims to the existence of a foundational truth are undermined. In essence, such seeming mutual and procedural fairness hides substantive injustices. A paradox seems to be inherent in social theory's self-referential approach to religion, and is an additional manifestation of its dominative idiosyncrasies. This may shed new light on the Qur'anic verse:

Never will the Jews or the Christians be satisfied with thee unless thou follow their form of religion. (2:120) 
In addition to being a Qur'anic cautioning, this verse offers methodological insights into the self-referential, self-propelling identity structure of the "other." This is not necessarily due to the existence of malice, but rather despite the absence of any. As such there may be no reason to attribute self-conscious malicious motives to the author himself who could only be limited by his own civilizational horizons.

Furthermore, while van Nieuwenhuijze's observation that both Arab/Islamic and European civilizations face a crisis may carry some truth in it, a problem lies in what is not being said. If the historical dynamics of both civilizations, judged by past experiences, is any indication of the opposite directions both encounter, then it is very possible that the current crisis is a continuous reflection of opposing dynamics. On the one hand, a nonfoundational postmodern civilization desperately seeking anchorage, may be experiencing the pains of old age. On the other hand, a foundational civilization seeking the restoration of its dynamic impulse may be undergoing the pangs of rebirth. While both are in pain/crisis, in and of itself, this does not tell much. This contention may raise highly speculative issues beyond the scope of this review. However, the point to be made is that a sense of mutual crises need not, by itself, justify an interactional approach and in some cases may provoke the obverse. For instance, despite all the globalization rhetoric that is instrumentalized as justification for One World interaction, this "emerging" phenomenon may be nothing more than the developmental discourse in a new guise, reflecting the superstructural/ideological manifestation of an economistic infrastructure-in short, an advanced and final stage of Western technological economism. Global interactionism may end up only reproducing the promises and failures of development theory. Condescending calls for the participation of the "other" are likely to conjure up results no different than those of earlier calls for joining the Western "modern" experience.

One significant catch with the proposition of intercultural exchange is that as an open cognitive exercise it cannot take place in the absence of a normative closure. For meaningful communication to occur, problems of legitimacy in the Arab/Muslim world will have to be initially addressed and resolved. To both their people and the "other," Arab regimes stand on shaky grounds. This prohibits them from making credible claims to authentic representations of themselves. With the exception of Iran, no other Arab or Muslim state has acquired the normative-cognitive preconditions for an equitable dialogue-not in the sense that a dialogue has to await a symmetrical relationship, but that at least some basic domestic homework needs to be done before meaningful interaction may be possible. This is mainly an Arab/Muslim substantive problem which does not exonerate Arabs and Muslims from blame. 
A final point to add with regards to the current state of Oriental studies, at least at the academic level, has to do with its ordering of variables. Whereas the study of the East necessitates that "qualified" Easterners speak for themselves (independent variable), while the Westerners try to learn and understand (dependent variable), with the Western educated Easterners set as facilitators (intervening variable), this order has not as of yet been effectuated. The latter two continue to act as explanatory/independent variables. By the same token, this order may be reversed if an Occidental field of study is to develop. A meaningful interaction could take place only subsequent to this pair of initial stages.

Being latecomers, however, Arabs/Muslims may still have to undergo the process of observing the West on their own, so that at a more advanced stage, when receiving self-representative information by the Occident about the "West," they may be able to compare their own findings with that which is incoming, i.e., developing a discipline of empirical comparative studies. If one may suggest an initial step in this direction, the Occident need not be perceived, as many Arabs/Muslims do and as many Occidentals represent themselves, solely as a monolith.

For purposes of precision and observation, it may be of benefit to classify the West along some qualifying attributes, for instance, among other current possibilities: the imperial West (e.g., the United States); the semi-imperial West (e.g., the United Kingdom and France); and the nonimperial West (e.g., Germany and most other European countries). Such classifications must remain fluid as actor and thought roles and patterns change over time. However, they may reflect a kind of constraint on intellectual simplicity while introducing elements of analytical complexity and sophistication. The idea behind the exercise is to identify historical antecedents to imperialism and then move backward, through the medium of Western thought, to observe its impact on the concept of "Europe" or "the West" as manifestations of an evolutionary dynamic, and contrariwise speculate about alternative outcomes had the Occident been deprived of its imperial historical fragment, pointing out what this could mean or imply (both in the past and present).

In short, what would the West have metamorphized into without the colonial experience and the circumstantial discovery of the New World, and could it shed its imperial impulse without being true to itself? Is imperialism (intellectual and/or physical) a cause or effect of Western reality? The speculative burden of such questions may render them less amenable to emphatic conclusions, yet it remains important as an heuristic and promising device toward a better understanding of the West. How these questions are answered could shed new perspectives on the inherent and self-propelling dynamics at play in the 
Occident and which Arabs/Muslims will have to tackle beyond imitation, wishful thinking, and proposed dialogues.

Amr G. E. Sabel University of Calgary,

Calgary, Alberta

Canada 